\title{
Pancreatic Carboxyl Ester Lipase: A Circulating Enzyme That Modifies Normal and Oxidized Lipoproteins In Vitro
}

\author{
Raanan Shamir, ${ }^{\star}$ William J. Johnson, ${ }^{\star}$ Kelly Morlock-Fitzpatrick, ${ }^{\star}$ Reza Zolfaghari, ${ }^{\star}$ Ling Li, ${ }^{\S}$ Eric Mas, \\ Dominique Lombardo," Diane W. Morel, ${ }^{\star}$ and Edward A. Fisher ${ }^{\star}$ \\ *Department of Biochemistry, Medical College of Pennsylvania and Hahnemann University, Philadelphia, Pennsylvania 19129; ${ }^{\ddagger}$ Division \\ of Gastroenterology and Nutrition, The Children's Hospital of Philadelphia, Philadelphia, Pennsylvania 19104; ${ }^{\S}$ Cardiovascular Institute, \\ Mount Sinai School of Medicine, New York 10029; and INSERM U260, Faculté de Médicine, 13385 Marseille, France
}

\begin{abstract}
Pancreatic carboxyl ester lipase (CEL) hydrolyzes cholesteryl esters (CE), triglycerides (TG), and lysophospholipids, with CE and TG hydrolysis stimulated by cholate. Originally thought to be confined to the gastrointestinal system, CEL has been reported in the plasma of humans and other mammals, implying its potential in vivo to modify lipids associated with LDL, HDL (CE, TG), and oxidized LDL (lysophosphatidylcholine, lysoPC). We measured the concentration of CEL in human plasma as $1.2 \pm 0.5 \mathrm{ng} / \mathrm{ml}$ (in the range reported for lipoprotein lipase). Human LDL and $\mathrm{HDL}_{3}$ reconstituted with radiolabeled lipids were incubated with purified porcine CEL without or with cholate (10 or $100 \mu \mathrm{M}$, concentrations achievable in systemic or portal plasma, respectively). Using a saturating concentration of lipoprotein-associated CE $(4 \mu \mathrm{M})$, with increasing cholate concentration there was an increase in the hydrolysis of LDL- and $\mathrm{HDL}_{3}$-CE; at $100 \mu \mathrm{M}$ cholate, the percent hydrolysis per hour was $32 \pm 2$ and $1.6 \pm 0.1$, respectively, indicating that CEL interaction varied with lipoprotein class. $\mathrm{HDL}_{3}$-TG hydrolysis was also observed, but was only $\sim 5$ $10 \%$ of that for $\mathrm{HDL}_{3}-\mathrm{CE}$ at either 10 or $100 \mu \mathrm{M}$ cholate. Oxidized LDL (OxLDL) is enriched with lysoPC, a proatherogenic compound. After a 4-h incubation with CEL, the lysoPC content of OxLDL was depleted 57\%. Colocalization of CEL in the vicinity of OxLDL formation was supported by demonstrating in human aortic homogenate a cholate-stimulated cholesteryl ester hydrolytic activity inhibited by anti-human CEL IgG. We conclude that CEL has the capability to modify normal human LDL and HDL composition and structure and to reduce the atherogenicity of OxLDL by decreasing its lysoPC content. (J. Clin. Invest. 1996. 97:1696-1704.) Key words: low density lipoprotein • high density lipoprotein • oxidized low density lipoprotein • aorta $\cdot$ lysophosphatidyl choline
\end{abstract}

\footnotetext{
Address correspondence to Dr. Edward A. Fisher, Mount Sinai Cardiovascular Institute, The Rockefeller University, Box 4, 1230 York Ave., New York, NY 10021. Phone: 212-327-7452; FAX: 212-3277454; E-mail: fisher@rockvax.rockefeller.edu

Received for publication 21 September 1995 and accepted in revised form 16 January 1996.
}

J. Clin. Invest.

(C) The American Society for Clinical Investigation, Inc.

0021-9738/96/03/1696/09 \$2.00

Volume 97, Number 7, April 1996, 1696-1704

\section{Introduction}

Modification by lipases, such as hepatic lipase (1), lipoprotein lipase (2), and phospholipase A2 (3), alters the composition, structure, and function of lipoproteins. Neglected in this regard is the pancreatic carboxyl ester lipase (CEL, ${ }^{1}$ sometimes referred to as bile salt-dependent cholesteryl ester hydrolase), whose primary function is thought to be hydrolysis of dietary lipid esters in the intestinal lumen (for a recent review, see reference 4).

One reason for this neglect may be the lack of appreciation that CEL activity is expressed outside of the pancreas in a number of mammalian species. For example, there are reports of CEL activity and/or mRNA in rat liver (e.g., references 5-7), human breast (8), human hepatocarcinoma HepG2 cells (9), human placenta (10), rat (11) and rabbit heart (12), and rat and rabbit aorta $(13,14)$. Particularly intriguing is the evidence that CEL is found in the blood plasma of a number of mammals, including humans (15), rats (11), dogs, and goats (16). Implied, then, is that lipoproteins in the circulation or interstitium could be potential targets for CEL and also that circulating CEL, which has a heparin binding site (17), may become associated with a variety of tissues, independent of their capacity to synthesize the enzyme, by associating with cell-surface proteoglycans. The consequences of CEL-mediated lipoprotein modification are suggested by recent reports that $(a)$ the treatment in vitro of LDL by nonmammalian cholesteryl esterases depletes LDL of core cholesteryl esters (18) and leads to increased net transfer of LDL-cholesterol to cells (19), and (b) CEL secreted by HepG2 cells increases the cellular uptake of cholesteryl esters from HDL (20).

In addition to its activity against the dietary lipids cholesteryl ester (CE), triglyceride (TG), and retinyl ester, CEL has significant activity against lyosophospholipids and, in fact, was originally cloned as the pancreatic lysophospholipase (21). Thus, it is plausible that CEL may modify not only the core CE or TG of a normal lipoprotein, but also the lysophosphatidylcholine (lysoPC) of oxidized LDL (OxLDL). Given the major roles attributed to lysoPC in the promotion of atherosclerotic disease (such as enhanced monocyte chemotaxis [22], mitogenic stimulation of macrophages [23], and inhibition of endothelium-dependent arterial relaxation [24]) and the reports that CEL activity was found in rat and rabbit aortae $(13,14)$, CEL could serve as a protective factor in vascular tissue

1. Abbreviations used in this paper: $\mathrm{CE}$, cholesteryl ester; CEL, carboxyl ester lipase; $\mathrm{HDL}_{3}$, HDL, subclass 3 ; LpL, lipoprotein lipase; lysoPC, lysophosphatidylcholine; OxLDL, oxidized LDL; PC, phosphatidylcholine; TBARS, thiobarbituric acid-reactive substances; TG, triglyceride or triacylglycerol. 
against the adverse effects of OxLDL. Supporting this hypothesis are the recent reports that the treatment of OxLDL with a bacterial lysophospholipase reduced the antagonism by lysoPC of the endothelial-dependent relaxation response to acetylcholine of aortic rings $(24,25)$. Since oxidation of $\mathrm{LDL}$ is thought to occur not in plasma but within arterial tissue (26), aortic CEL activity would be in the appropriate location to serve as a protective factor.

In the studies summarized in this report, we have demonstrated: $(a)$ the ability of CEL to hydrolyze the core lipids of human LDL and HDL using bile salt concentrations that can occur outside of the intestinal lumen in healthy individuals; $(b)$ the ability of CEL to reduce the lysoPC content of human OxLDL; $(c)$ the presence of CEL in human plasma; and $(d)$ the presence of an activity in human aortic homogenate with enzymatic and immunological properties indistinguishable from CEL. The results strongly suggest that CEL plays a wider role in lipid and lipoprotein metabolism than previously appreciated both in terms of enzymatic targets and tissue distribution.

\section{Methods}

All chemicals were the highest grade commercially available and purchased from Sigma Chemical Co. (St. Louis, MO), unless otherwise noted. Cholesteryl $\left[1-{ }^{14} \mathrm{C}\right]$ oleate (supplied with specific activity of $53.4 \mathrm{mCi} / \mathrm{mmol})$, [carboxyl- ${ }^{14} \mathrm{C}$ ]triolein $(112 \mathrm{mCi} / \mathrm{mmol})$, and [palmitoyl- $\left.1{ }^{14} \mathrm{C}\right]$ lysopalmitoyl phosphatidylcholine $(56.7 \mathrm{mCi} / \mathrm{mmol})$ were purchased from New England Nuclear (Boston, MA). [1 $1 \alpha, 2 \alpha(n)$ $\left.{ }^{3} \mathrm{H}\right]$ cholesteryl oleate (specific activity of $49.6 \mathrm{Ci} / \mathrm{mmol}$ ) was purchased from Amersham (Arlington Heights, IL). Porcine pancreatic CEL was purified as reported previously (27). Reagents for lipoprotein electrophoresis were obtained from Beckman (Fullerton, CA).

The procedures for obtaining human blood samples have been approved by the Committee for Protection of Human Subjects at the Medical College of Pennsylvania and the donors have signed informed consent forms.

\section{Reconstitution of human lipoproteins with radiolabeled lipids}

Lipoprotein fractions were isolated from the plasma of normal human volunteers using sequential density gradient centrifugation $(28$, 29). $\mathrm{HDL}_{3}$ was delipidated with ethanol/diethyl ether (3:2 vol $\left./ \mathrm{vol}\right)$ at $0^{\circ} \mathrm{C}(30)$ and the apoproteins reserved for the reconstitution step (see below). The ethanol/diethyl ether lipid extracts were dried by rotary evaporation and stored in 2:1 chloroform/methanol. To incorporate cholesteryl $\left[{ }^{14} \mathrm{C}\right]$ oleate or $\left[{ }^{14} \mathrm{C}\right]$ triolein into $\mathrm{HDL}_{3}$, the labeled compounds were added directly to the lipid extract, which was then reconstituted with $\mathrm{HDL}_{3}$ apoproteins by sonication (31). The reconstituted $\mathrm{HDL}_{3}$ had a final specific activity of $\sim 0.022 \mu \mathrm{Ci}$ of cholesteryl $\left[1-{ }^{14} \mathrm{C}\right]$ oleate per $\mu \mathrm{mol} \mathrm{CE}$ or $\sim 7 \mu \mathrm{Ci}$ of $\left[\right.$ carboxyl- $\left.{ }^{14} \mathrm{C}\right]$ triolein per $\mu \mathrm{mol}$ TG.

$\left[1 \alpha, 2 \alpha(n)-{ }^{3} \mathrm{H}\right]$ cholesteryl oleate was incorporated into LDL by the potato-starch method of Krieger et al. (32). The final specific activity was $\sim 0.10 \mu \mathrm{Ci}$ of $\left[1 \alpha, 2 \alpha(n)-{ }^{3} \mathrm{H}\right]$ cholesteryl oleate per $\mu \mathrm{mol}$ LDL-CE.

\section{Analysis of reconstituted and native human lipoproteins}

For reconstituted lipoproteins, lipids were extracted by the procedure of Bligh and Dyer (33). Phospholipid was determined by the method of Sokoloff and Rothblat (34). Protein was assayed by a modification of the Lowry technique (35). Cholesterol (free and total) was determined by gas-liquid chromatography using choelsteryl methyl ether as an internal standard (36). Esterified cholesterol was calculated by subtracting free cholesterol from total cholesterol. TG was determined by the Sigma triglyceride diagnostic kit, using glycerol as a standard. In some experiments, the cholesterol content (total, free, ester) of native LDL was determined as above. Agarose electro- phoresis of native and reconstituted lipoproteins and gel staining by Sudan black were performed using Beckman Paragon Lipo Gel materials.

\section{Preparation and characterization of oxidized human $L D L$}

Human LDL, isolated as above, was oxidized by a 7-h incubation with $\mathrm{Cu}^{2+}(5 \mu \mathrm{M}$ above EDTA concentration [37]). Butylated hydroxytoluene $(20 \mu \mathrm{M})$ was then added to stop any further oxidation. The cholesterol content of LDL and OxLDL was determined enzymatically by the Sigma cholesterol diagnostic kit No. 352. Protein content was assayed using a modification of the Lowry technique (35). The cholesterol contents of LDL and OxLDL were $1.4 \mathrm{mg}$ and $1.2 \mathrm{mg} / \mathrm{mg}$ protein, respectively. The protein concentrations of LDL and OxLDL were 1.4 and $1.3 \mathrm{mg} / \mathrm{ml}$, respectively. The extent of lipid peroxidation was estimated as thiobarbituric acid-reactive substances (TBARS) as described previously (38). Briefly, LDL or OxLDL (50 $\mu \mathrm{g}$ protein of either) and various amounts of standard (1,1,3,3-tetramethoxypropane) were mixed with $1 \mathrm{ml}$ of $25 \%$ trichloroacetic acid and $1 \mathrm{ml}$ of $1 \% 2$-thiobarbituric acid containing $5 \mu \mathrm{M} \mathrm{CuSO}_{4}$. The mixture (final volume of $0.4 \mathrm{ml}$ ) was incubated at $95^{\circ} \mathrm{C}$ for $45 \mathrm{~min}$ and centrifuged at $1,500 \mathrm{rpm}$ at $10^{\circ} \mathrm{C}$ for $30 \mathrm{~min}$ to remove any insoluble material. The $\mathrm{OD}_{532}$ of the supernatant was determined and the amount of TBARS was expressed as nanomoles of malondialdehyde equivalents per milliliter of reaction mixture.

\section{Human tissue collection and preparation}

Male and female aortic arch samples were obtained at autopsy and frozen immediately in liquid $\mathrm{N}_{2}$ and then stored at $-70^{\circ} \mathrm{C}$ until analyzed. Under the Institutional Review Board guidelines autopsy samples are collected so that neither the identity nor cause of death of subjects was revealed to us. To prepare samples for enzymatic analysis frozen tissues were thawed on ice. Adherent vascular and membranous materials were dissected away and the remaining tissue dispersed at $4^{\circ} \mathrm{C}$ in $3 \mathrm{vol}$ of $0.25 \mathrm{M}$ sucrose at full speed for $1 \mathrm{~min}$ in a homogenizer (Tekmar Co., Cincinnati, OH). Aliquots were stored frozen at $-70^{\circ} \mathrm{C}$ until enzymatic assays were performed (see below).

\section{Assay of the hydrolysis of CE, TG, or lysoPC}

All activity determinations were done in duplicate with a variability coefficient $<10 \%$.

$C E$ and $T G$. For reconstituted lipoproteins, the hydrolysis of $\mathrm{CE}$ or TG was determined based on radiometric procedures described previously $(11,39)$. For substrates dispersed in ethanol, the reaction mixture had a final volume of $0.2 \mathrm{ml}$; for substrates in LDL or $\mathrm{HDL}_{3}$, the final volume was $1 \mathrm{ml}$. The final concentration of Tris-maleate (pH 7.0) was $50 \mathrm{mM}$, and sodium cholate was either 0,10 , or $100 \mu \mathrm{M}$. Reactions were initiated by addition of purified CEL and labeled substrate (to the concentrations given in Results) and incubated at $37^{\circ} \mathrm{C}$ for the lengths of time also given in Results. The released $\left[{ }^{14} \mathrm{C}\right]$ oleate was extracted as described previously (11) and quantitated by scintillation counting. Results are typically expressed in units of $1 \mathrm{pmol}$ fatty acid released/h/ $/ \mathrm{g}$ CEL. To examine the effect of CEL on the hydrolysis of CE of native LDL a similar protocol was performed, but the reaction volume was $5 \mathrm{ml}$ and cholesterol (total, free, ester) was assayed as in the above section, Analysis of reconstituted and native human lipoproteins.

For analysis of aortic homogenates, $50 \mu \mathrm{l}$ of an appropriately diluted homogenate was used as the enzyme source. The final reaction volume was $0.2 \mathrm{ml}$ and the concentration of Tris-maleate $(\mathrm{pH} 7.0)$ was $50 \mathrm{mM}$. Cholate or deoxycholate was added at a concentration ranging from 0 to $100 \mathrm{mM}$ as indicated in Results. The reactions were initiated by addition of $0.01 \mathrm{ml}$ ethanol containing $2 \mathrm{nmol}$ of cholesteryl $\left[1-{ }^{14} \mathrm{C}\right]$ oleate with a specific activity of $25 \mu \mathrm{Ci} / \mu \mathrm{mol}$. The tubes were incubated at $37^{\circ} \mathrm{C}$ for $30 \mathrm{~min}$. The released $\left[{ }^{14} \mathrm{C}\right]$ oleate was extracted and quantitated as above. Results are expressed in units of 1 $\mathrm{nmol}\left[{ }^{14} \mathrm{C}\right]$ oleate released/h/gram of tissue.

To investigate the inhibition of aortic homogenate CEL activity by a rabbit IgG directed against human CEL, the following experi- 
ment was performed. Aortic homogenate was preincubated overnight at $4^{\circ} \mathrm{C}$ with $5 \mu \mathrm{g}$ of either rabbit anti-human CEL $(40,41)$ or rabbit preimmune IgG. The samples were then assayed for CEL activity as described above.

LysoPC. Lysophospholipase activity was measured using the method described by Vanden Bosch et al. (42). Substrate and either buffered enzyme (porcine pancreatic CEL or bacterial 2-lysophosphatidylcholine acylhydrolase [EC 3.1.1.5; Sigma]) or buffer alone (potassium phosphate $0.1 \mathrm{M}$ ) were diluted with $\mathrm{dH}_{2} \mathrm{O}$ to a final volume of $0.4 \mathrm{ml}$ and a final potassium phosphate concentration of 200 $\mathrm{mM}$. In some cases, to determine the presence of endogenous lysophospholipase activities of LDL and OxLDL, these lipoproteins were substituted for the enzyme source.

The reaction was started by adding $200 \mathrm{nmol}(0.1 \mathrm{ml}$ of a $2 \mathrm{mM}$ aqueous solution) of the substrate [palmitoyl-1-14C]lysopalmitoyl phosphatidylcholine with specific activity of $26.1 \times 10^{-3} \mu \mathrm{Ci} / \mu \mathrm{mol}$. After $10 \mathrm{~min}$ at $37^{\circ} \mathrm{C}$, the reaction was stopped with $2.5 \mathrm{ml}$ of modified Dole's solution (43). Approximately $100 \mathrm{mg}$ of silica gel (100-200 mesh) was added, followed by $1.5 \mathrm{ml}$ of heptane and $1.5 \mathrm{ml}$ of water. After each addition, the tube was vortexed for $15 \mathrm{~s} .1 \mathrm{ml}$ of the resulting upper phase, which contained the labeled fatty acid released from lysoPC by hydrolysis, was taken for scintillation counting. Results are expressed in nanomoles of fatty acid released per minute per milligram of protein. Hydrolysis of lysoPC at a final concentration of 80 $\mu \mathrm{M}$ (similar to the concentration of OxLDL-associated lysoPC in the experiments described below) was also assayed, but with $4 \mu \mathrm{g} / \mathrm{ml}$ of CEL and for incubation times up to $240 \mathrm{~min}$. The percent hydrolysis at each time point was calculated from the scintillation counting data.

In pilot experiments, the potential for CEL to act as a phospholipase was investigated using both radiolabeled phosphatidylcholine (PC) and HDL reconstituted with radiolabeled PC. No activity above background was detected in either case.

\section{Effect of CEL on the lysophospholipid content of OxLDL}

Human lipoproteins (LDL, OxLDL) containing $\sim 0.5 \mathrm{mg}$ protein $/ \mathrm{ml}$ were incubated with either $4 \mu \mathrm{g}$ CEL protein $/ \mathrm{ml}$ or $1 \mu \mathrm{g} / \mathrm{ml}$ bacterial 2-lysophosphatidylcholine acylhydrolase or buffer alone (potassium phosphate, $200 \mathrm{mM}$ final concentration) for $4 \mathrm{~h}$ at $37^{\circ} \mathrm{C}$. At time points $(0,1,2$, and $4 \mathrm{~h})$ the reaction was stopped with $1 \mathrm{ml}$ methanol and lipids were extracted using the procedure of Bligh and Dyer (33). The phospholipids were separated by TLC on silica gel G $(250 \mu \mathrm{m}$ as Uniplate $^{\mathrm{TM}}$; Analtech Inc., Newark, DE) with two solvent systems used in the same dimension: chloroform/methanol/water, 65:35:6 ( $\mathrm{vol} / \mathrm{vol} / \mathrm{vol})$ and chloroform/acetone/methanol/acetic acid/water, 6:8: 2:2:1. After visualization with iodine vapor, PC and lysoPC bands were scraped from the plates and assayed for inorganic phosphorus content according to the method of Sokoloff and Rothblat (34). Each TLC plate had lanes containing unlabeled and labeled standards to localize the desired bands in the sample lanes. Quantitative recovery of lysophospholipids was confirmed in some experiments by adding trace amounts of lysoPC to samples before lipid extraction and TLC separation.

\section{Detection of circulating CEL in human serum}

The amount of CEL in human serum samples was determined by ELISA as described previously (15). Briefly, wells of immunoplates (Nunc, Roskilde, Denmark) were coated with a $10 \mu \mathrm{g} / \mathrm{ml}$ solution $(0.1$ $\mathrm{M}$ carbonate buffer, $\mathrm{pH}$ 9.5) of anti-human CEL polyclonal antibodies rased in rabbit $(40,41)$. After overnight incubation at $4^{\circ} \mathrm{C}$, wells were washed three times for $30 \mathrm{~min}$ at $37^{\circ} \mathrm{C}$ with $0.05 \%$ Tween 20 in PBS (PBS/Tween). Then, 100- $\mu$ l portions of each sample (either human serum or pure human CEL standard), appropriately diluted in $\mathrm{PBS} /$ Tween, were added to the wells and incubated for $30 \mathrm{~min}$ at $37^{\circ} \mathrm{C}$. After three washes with PBS/Tween, $100 \mu \mathrm{l}$ of biotin-labeled rabbit polyclonal antibodies to human CEL $(2 \mu \mathrm{g} / \mathrm{ml})$ was added to each well and incubated for $2 \mathrm{~h}$ at $37^{\circ} \mathrm{C}$. After three washes with PBS/ Tween, dilute alkaline phosphatase-avidin conjugates were added $(100 \mu \mathrm{l} /$ well $)$ and incubated for $2 \mathrm{~h}$ at $37^{\circ} \mathrm{C}$. After three washes with
PBS/Tween, $100 \mu \mathrm{l}$ of $p$-nitrophenyl phosphate $(1 \mathrm{mg} / \mathrm{ml}$ in $0.2 \mathrm{M}$ Tris/ $\mathrm{HCl}, \mathrm{pH} 8.5,1 \mathrm{mM} \mathrm{CaCl}_{2}$, and $1 \mathrm{mM} \mathrm{MgCl}_{2}$ ) was added to each well and incubated for $1 \mathrm{~h}$ at $37^{\circ} \mathrm{C}$. The degree of color development was determined by reading the plate in an MR 5000 spectrophotometer (Dynatech Laboratories Inc., Chantilly, VA) at $405 \mathrm{~nm}$ and comparing the serum values with the standard curve based on the assay results for serially diluted samples of the pure human CEL.

\section{Data analysis}

Unless otherwise indicated, data are expressed as mean values \pm SD and statistical comparisons made by the Student's $t$ test or ANOVA. The software program InStat (GraphPAD Software for Science, San Diego, CA) was used for testing statistical significance.

\section{Results}

\section{CEL is a circulating lipase in humans}

CEL activity or mass has been reported in the plasma of rats (11), dogs, goats (16), and humans (15). We were interested in confirming that CEL is a circulating enzyme in humans. Plasma CEL mass was measured in six normal volunteers by a quantitative ELISA assay (15). The average concentration was $1.2 \pm 0.5 \mathrm{ng} / \mathrm{ml}$ (range $0.6-2.0$ ), consistent with literature values (15) and in the range reported for lipoprotein lipase (LpL) (44).

\section{The effects of CEL on normal lipoproteins}

Properties of reconstituted human $\mathrm{HDL}_{3}$ and $L D L$. The reconstitution of normal human $\mathrm{HDL}_{3}$ and LDL included radiolabeled CE. Since human HDL also contains small amounts of TG, some $\mathrm{HDL}_{3}$ was also reconstituted with $\left[{ }^{14} \mathrm{C}\right] \mathrm{TG}$ as the only labeled core lipid. As shown in Table I, the chemical compositions of the reconstituted lipoproteins resembled the reported values for native human lipoproteins (45). In addition, we tested whether the cholate concentrations used in the experiments described below would significantly affect the physical properties of the reconstituted lipoproteins. The agarose gel electrophoretic mobilities of reconstituted LDL and $\mathrm{HDL}_{3}$ were not affected by treatment with 10 or $100 \mu \mathrm{M}$ cholate (data not shown), indicating that the bile acid did not cause major disruptions of the structure of these lipoproteins.

Characterization of the action of CEL on the CE of $H D L_{3}$. Since CE is the major core lipid in HDL, and this lipoprotein is relatively simple to reconstitute, we used $\left[{ }^{14} \mathrm{C}\right] \mathrm{CE}$-labeled $\mathrm{HDL}_{3}$ to establish appropriate reaction conditions for examining lipoprotein modification by CEL. Previous studies of lipoproteins modified by cholesteryl esterases have typically used enzymes in the milligrams per milliliter range (e.g., references

Table I. Chemical Compositions of Human $\mathrm{HDL}_{3}$ and $\mathrm{LDL}$ Reconstituted with Labeled Core Lipids

\begin{tabular}{lccc}
\hline & $\begin{array}{c}\mathrm{LDL} \\
{\left[{ }^{3} \mathrm{H}\right] \mathrm{CE}}\end{array}$ & $\begin{array}{c}\mathrm{HDL}_{3} \\
{\left[{ }^{4} \mathrm{C}\right] \mathrm{CE}}\end{array}$ & $\begin{array}{c}\mathrm{HDL}_{3} \\
{\left[{ }^{14} \mathrm{C}\right] \text { Triolein }}\end{array}$ \\
\hline Protein & $27.4 \pm 2.1$ & $48.0 \pm 0.07$ & $41.0 \pm 0.05$ \\
Phospholipid & $29.8 \pm 1.6$ & $32.2 \pm 0.04$ & $32.4 \pm 0.90$ \\
CE & $23.7 \pm 1.4$ & $15.4 \pm 1.20$ & $20.3 \pm 1.53$ \\
Cholesterol & $15.3 \pm 1.5$ & $2.90 \pm 0.05$ & $3.78 \pm 0.11$ \\
TG & $3.84 \pm 0.63$ & $1.57 \pm 0.03$ & $2.52 \pm 0.18$ \\
& & & \\
\hline
\end{tabular}

The chemical composition was determined in triplicate and is given as percentage \pm SD of total weight. 
18 and 19). However, given the similar concentrations in human plasma of LpL and CEL noted above, we decided to use a concentration in the micrograms per milliliter range, similar to those used in studies of LpL-lipoprotein interactions in vitro (e.g., references 46 and 47). The next choice was the range of cholate concentration. The concentration of bile acid in human plasma is in the range of $10 \mu \mathrm{M}(48)$ and is $\sim 10$-fold higher in postprandial portal plasma (49). Thus, cholate concentrations of 0,10 , and $100 \mu \mathrm{M}$ were used.

With the chosen CEL and cholate concentrations, the dependences of $\mathrm{HDL}_{3}-\mathrm{CE}$ hydrolysis on incubation time and substrate concentration were examined. Independent of cholate concentration, the hydrolysis of $\mathrm{CE}$ did not approach a plateau until after 60 min (Fig. $1 A$ ), but clearly saturated at a $\mathrm{CE}$ concentration of $4 \mu \mathrm{M}$ (Fig. $1 B$ ). These parameters of incubation time $(60 \mathrm{~min})$ and lipid concentration $(4 \mu \mathrm{M})$ were maintained in subsequent testing of the effects of CEL on the rates of hydrolysis of $\mathrm{HDL}_{3}-\mathrm{TG}$ and $\mathrm{LDL}-\mathrm{CE}$ in order to make comparisons among results obtained under identical conditions.

The effects of substrate presentation on CEL-mediated hydrolysis of $C E$ and $T G$. Using the conditions defined above, $\mathrm{CE}$ was presented to CEL in one of the following forms: $(a)$ dispersed in EtOH, (b) associated with $\mathrm{HDL}_{3}$, or $(c)$ associated with LDL. In addition, TG was presented in either form a or b.

The results are summarized in Table II. Note that for all forms of substrate presentation, $10 \mu \mathrm{M}$ cholate significantly stimulated hydrolysis in comparison to the no cholate control. In all but one case $\left(\mathrm{HDL}_{3}-\mathrm{CE}\right)$, increasing the cholate concentration from 10 to $100 \mu \mathrm{M}$ further stimulated hydrolytic activity. It is also interesting to note that for EtOH-CE or LDL-CE, at either concentration of cholate, the hydrolysis was comparable and greatly exceeded that observed for $\mathrm{HDL}_{3}$-CE. Similarly, the hydrolysis of EtOH-TG was significantly greater than that of $\mathrm{HDL}_{3}$-TG.

These results suggested that modest amounts of CEL could
Table II. Hydrolysis by Pancreatic CEL of CE and TG Dispersed in Ethanol or Associated with Lipoproteins $(\mathrm{pmol} / \mathrm{h} / \mu \mathrm{g} C E L$ Protein $\pm S D)$

\begin{tabular}{cccc}
\hline & No cholate & $10 \mu \mathrm{M}$ cholate & $100 \mu \mathrm{M}$ cholate \\
\hline Ethanol & & & \\
CE & ND & $110 \pm 9$ & $4049 \pm 490$ \\
TG & ND & $3980 \pm 1044$ & $8518 \pm 2168$ \\
LDL & & & \\
CE & $27 \pm 1$ & $185 \pm 16$ & $5818 \pm 345$ \\
HDL & & & \\
CE & $4 \pm 1$ & $20 \pm 2$ & $23 \pm 1$ \\
TG & $0.3 \pm 0.0$ & $1.2 \pm 0.3$ & $2.5 \pm 0.2$ \\
\hline
\end{tabular}

CEL activity was assayed at $37^{\circ} \mathrm{C}$ for 60 min using $(a) \mathrm{CE}(4 \mu \mathrm{M})$ dispersed in ethanol, $(b) \mathrm{TG}(4 \mu \mathrm{M})$ dispersed in ethanol, $(c)$ reconstituted LDL $(4 \mu \mathrm{M} \mathrm{CE}),(d)$ reconstituted $\mathrm{HDL}_{3}(4 \mu \mathrm{M} \mathrm{CE}),(e)$ reconstituted $\mathrm{HDL}_{3}(4 \mu \mathrm{M}$ TG). Purified CEL was used at $4 \mu \mathrm{g} / \mathrm{ml}$ except for substrates a and $\mathrm{c}$ when the cholate concentration was $100 \mu \mathrm{M}$; in these cases, the CEL concentration was $0.25 \mu \mathrm{g} / \mathrm{ml}$. ND, Activity above background not detected.

deplete the CE content of LDL to a greater extent than that of $\mathrm{HDL}_{3}$, given not only the increased fractional hydrolysis of LDL-CE, but also that the CE core of LDL is much larger than that of $\mathrm{HDL}_{3}$. In Table III are summarized experiments in which the fractional hydrolysis per hour of LDL-CE and $\mathrm{HDL}_{3}-\mathrm{CE}$ by CEL was measured. As shown, there was indeed an appreciable percentage of LDL-CE hydrolyzed over time at either cholate concentration. That hydrolysis of LDL-CE by CEL and its stimulation by cholate were not artifacts of the lipoprotein reconstitution procedure was supported by finding similar results with native LDL studied under the same conditions ( $4 \mu \mathrm{M}$ LDL-CE and $0.25 \mu \mathrm{g} / \mathrm{ml} \mathrm{CEL}$ ): at 0 and $100 \mu \mathrm{M}$ cholate, there were reductions in CE mass of $1.3 \%( \pm 0.7, n=$
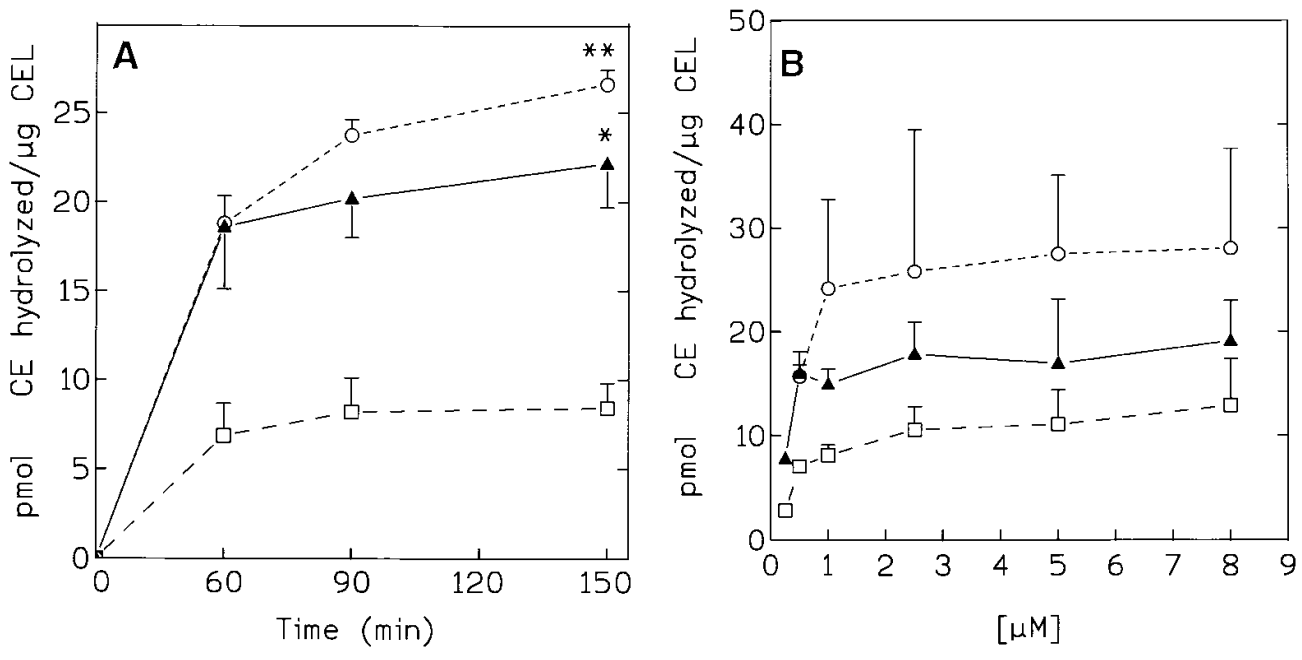

Figure 1. Dependence of CELmediated hydrolysis on incubation time and substrate concentration using reconstituted $\mathrm{HDL}_{3}$. $(A)$ CEL activity was measured at $37^{\circ} \mathrm{C}$ as described in Methods using reconstituted $\mathrm{HDL}_{3}(4 \mu \mathrm{M}$ CE). With 0 or 10 $\mu \mathrm{M}$ cholate, $4 \mu \mathrm{g} / \mathrm{ml}$ CEL was used. With $100 \mu \mathrm{M}$ cholate, the concentration of CEL was 0.25 $\mu \mathrm{g} / \mathrm{ml}$. The amount of $\left[{ }^{14} \mathrm{C}\right]$ oleate released was determined as described in Methods and expressed as picomoles per microgram of CEL. (B) CEL activity was measured as above, except the reaction time was $1 \mathrm{~h}$ and the amount of reconstituted $\mathrm{HDL}_{3}$ varied to supply the indicated CE concentrations. $\square$, no cholate; $\boldsymbol{\Lambda}, 10 \mu \mathrm{M}$ cholate; $\bigcirc$, $100 \mu \mathrm{M}$ cholate; *differs from 0 cholate at $P<0.01$; ** differs at $P<0.001$. 
Table III. Hydrolysis in $1 \mathrm{~h}$ by CEL of LDL- $\left.\beta^{3} H\right]$ cholesteryl Oleate (CO), $\left.\mathrm{HDL}_{3}-{ }^{14} \mathrm{C}\right] \mathrm{CO}$, or $\left.\mathrm{HDL}_{3^{-}}{ }^{14} \mathrm{C}\right]$ triolein (TO)

\begin{tabular}{lrcc}
\hline & \multicolumn{3}{c}{ Percent hydrolysis } \\
\cline { 2 - 4 }$[$ Cholate $]$ & LDL- $\left[{ }^{3} \mathrm{H}\right] \mathrm{CO}$ & $\mathrm{HDL}_{3}-\left[{ }^{14} \mathrm{C}\right] \mathrm{CO}$ & $\mathrm{HDL}_{3}-\left[{ }^{14} \mathrm{C}\right] \mathrm{TO}$ \\
\hline 0 & $2.1 \pm 0.1$ & $0.3 \pm 0.03$ & $0.03 \pm 0.007$ \\
$10 \mu \mathrm{M}$ & $14.6 \pm 1.3$ & $1.61 \pm 0.18$ & $0.06 \pm 0.01$ \\
$100 \mu \mathrm{M}$ & $32.0 \pm 1.9$ & $1.64 \pm 0.14$ & $0.10 \pm 0.03$
\end{tabular}

In a set of reactions separate from those summarized in Table II, hydrolysis by purified CEL was assayed using (a) reconstituted LDL $(4 \mu \mathrm{M}$ CE), (b) reconstituted $\mathrm{HDL}_{3}(4 \mu \mathrm{M} \mathrm{CE}),(c)$ reconstituted $\mathrm{HDL}_{3}(4 \mu \mathrm{M}$ TG). Purified CEL was used at $4 \mu \mathrm{g} / \mathrm{ml}$ except for substrate with cholate at a concentration of $100 \mu \mathrm{M}$; in this case, the CEL concentration was $0.25 \mu \mathrm{g} / \mathrm{ml}$.

4) and $35.0 \%( \pm 5.8, n=4)$, respectively.

In contrast to the LDL results, the percentage of the $\mathrm{HDL}_{3}$ - $\mathrm{CE}$ hydrolyzed under comparable conditions was relatively minor. Nonetheless, given the long half-life of HDL $(\sim 3 \mathrm{~d})$ in the human circulation (for review see reference 50 ), the extent of hydrolysis of HDL-CE in vivo may be underestimated by the results in vitro.

\section{The effects of CEL on OxLDL}

Characterization of lipoproteins. TBARs for LDL and OxLDL were $4.3 \pm 0.5(n=4)$ and $52.9 \pm 0.9(n=4) \mathrm{nmol}$ of malondialdehyde equivalents/mg protein, respectively. As expected, compared with LDL, OxLDL demonstrated increased anodic electrophoretic mobility (data not shown), reflecting a surface more negatively charged. In the absence of lipases, the PC and lysoPC contents of LDL and OxLDL did not change during $4 \mathrm{~h}$ of incubation.

Lysophospholipase activities of LDL and CEL. Lysophospholipase activity was determined using the assay described earlier (see Methods) under conditions of a saturating concentration of substrate. The endogenous activity of native or OxLDL was not different from background (data not shown). The activity of the porcine pancreatic CEL was 6,740 \pm 205 nmol of lysoPC hydrolyzed $/ \mathrm{min} / \mathrm{mg}$ protein $(n=4)$. As shown in Fig. 2, when CEL $(4 \mu \mathrm{g} / \mathrm{ml})$ was incubated with lysoPC in aqueous solution using a concentration similar to that of lysoPC associated with OxLDL, hydrolysis was $6.1 \% \pm 0.8$ and $47.2 \% \pm 4.7$ after $15 \mathrm{~min}$ and $4 \mathrm{~h}$, respectively.

Effect of CEL on lysoPC content of $O x L D L$. The lysoPC content of OxLDL was determined after $4 \mathrm{~h}$ of incubation with and without CEL. As shown in Fig. 3, the content of lysoPC was unchanged by incubation for $4 \mathrm{~h}$ without CEL, but after $4 \mathrm{~h}$ with CEL, the lysoPC content was significantly $(P<0.01)$ reduced to $43 \%$ of the initial value. Note that a comparable reduction was also obtained using the bacterial lysophospholipase (phospholipase B) used in previous studies (24). Thus, the lysoPC associated with OxLDL is available to the lysophospholipase activity of CEL.

CEL activity in human aorta. Because oxidation of LDL is thought to occur not in plasma but after the entry of LDL into the subintimal space of arterial tissue (26) the presence of CEL where OxLDL is generated and exerts it deleterious effects would be particularly significant. It has been reported previously that in rat and rabbit an activity resembling that of pan-

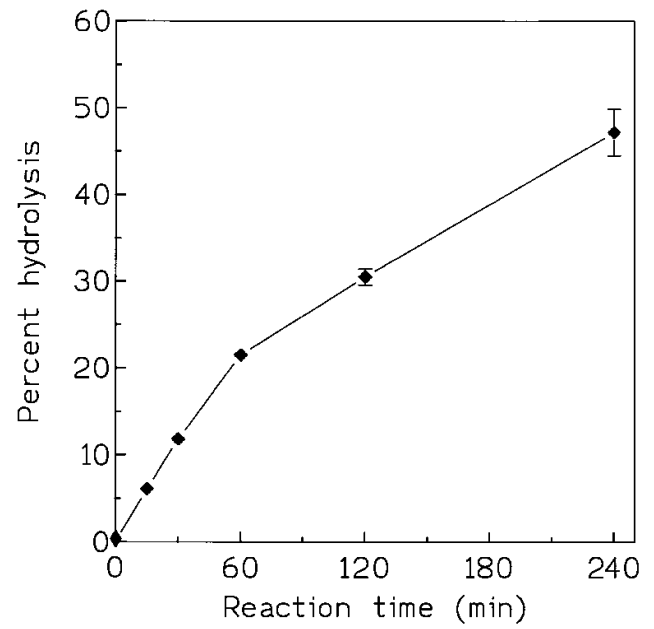

Figure 2. Percent hydrolysis by CEL of lysoPC. Lysophospholipase activity was measured as described in Methods. The concentrations of lysoPC and CEL were $80 \mu \mathrm{M}$ and $4 \mu \mathrm{g} / \mathrm{ml}$, respectively. The reactions were stopped at the indicated times, then the released fatty acids were extracted and quantitated as described in Methods. Percent hydrolysis was determined as $100 \times($ extracted cpm/total cpm $)$ and is presented as mean $\pm \mathrm{SD}, n=3$.

creatic CEL was present in aortic homogenate $(13,14)$. To pursue whether there is a similar activity in human aorta, tissue samples were obtained at autopsy. There was significant activity present in 10/11 males (for $n=11: 28.9 \pm 10.3 \mathrm{nmol} \mathrm{CE}$ hydrolyzed/h/gram of tissue, mean \pm SE; range of $0-122$ ) and $8 / 10$ females (for $n=10: 11.1 \pm 4.7$; range of $0-46.4$ ). Although there was a higher mean level in males, because of the interindividual variability the gender difference was not statistically significant, unless the analysis was restricted to 10 males and 8

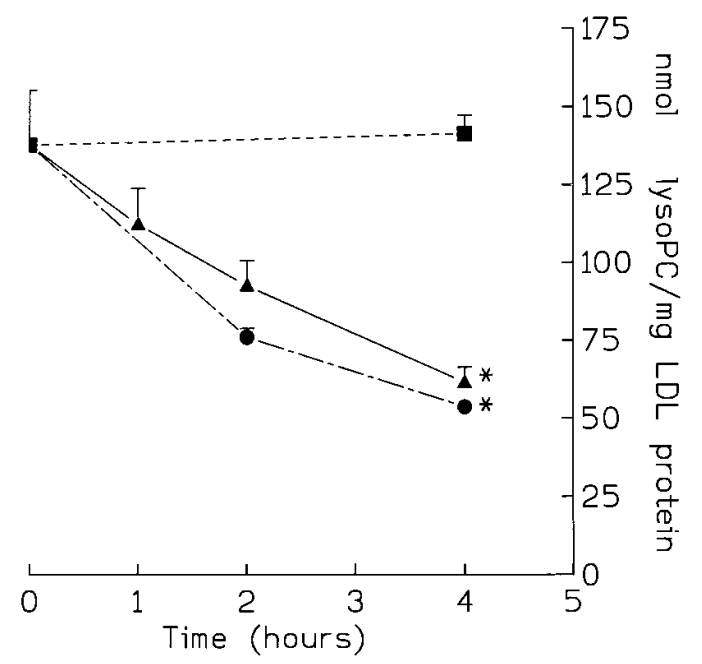

Figure 3. Effect of CEL on lysoPC content of OxLDL. OxLDL was incubated with either $4 \mu \mathrm{g} / \mathrm{ml}$ of CEL, $1 \mu \mathrm{g} / \mathrm{ml}$ of bacterial 2-lysophosphatidylcholine acylhydrolase, or buffer alone for $4 \mathrm{~h}$ at $37^{\circ} \mathrm{C}$. At the indicated times, the reaction was stopped and the lysoPC content remaining was determined as described in Methods. Results are given as mean $\pm \mathrm{SD}, n=6$. $\bullet$, bacterial 2-lysophosphatidylcholine acylhydrolase; $\boldsymbol{\Lambda}$, CEL; and $\mathbf{\square}$, buffer alone; *differs from buffer alone at $P<0.001$. 


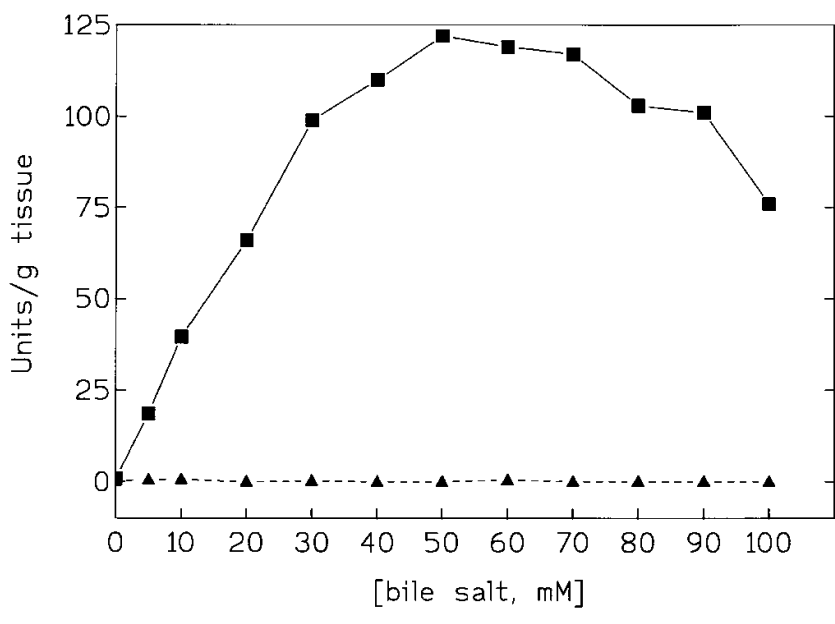

Figure 4. Cholesteryl ester hydrolase activity stimulated by trihydroxy bile salt in human aortic homogenate. CEL hydrolysis of CE in the presence of trihydroxy (cholate) or dihydroxy (deoxycholate) bile salt was determined in $50 \mu \mathrm{l}$ of human aortic homogenate as described in Methods. Cholate (ם) or deoxycholate ( $\mathbf{\Delta})$ was added at concentrations ranging from 0 to $100 \mathrm{mM} .1$ unit is $1 \mathrm{nmol}\left[{ }^{14} \mathrm{C}\right]$ oleate released/h/gram of tissue. Reactions were done in duplicate and the mean values are displayed.

females with detectable activity, in which case the male average $(n=10: 31.8 \pm 11.0)$ was significantly higher $(P<0.04)$ than the female average $(n=8: 13.8 \pm 5.5)$.

That the homogenate activity represented bona fide CEL was supported by two experiments. In the first, the maximal stimulation of the reaction by millimolar concentrations of trihydroxy (e.g., cholate) and not dihydroxy (e.g., deoxycholate) bile salts, a characteristic feature of CEL activity measured in vitro (5), was determined. As shown in Fig. 4, human aortic homogenate CEL activity increased with increasing concentration of cholate, but not deoxycholate. In the second type of experiment, the ability of an antibody raised against human CEL $(40,41)$ to inhibit the homogenate activity was tested. As

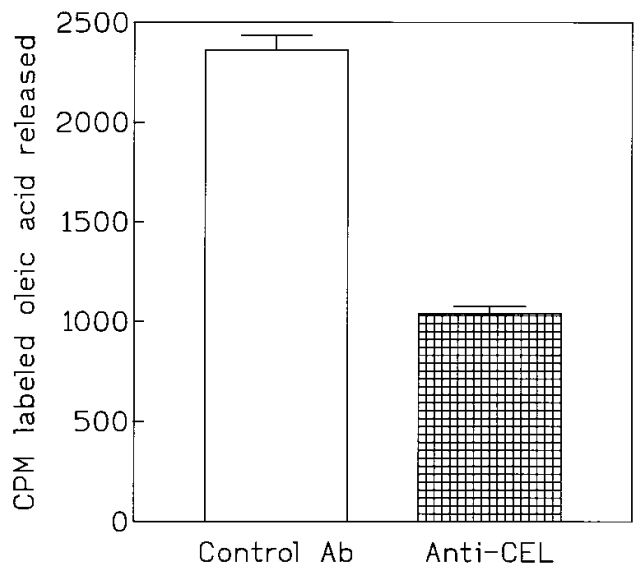

Figure 5. Effect of anti-CEL antibody on bile salt-dependent CEL activity in human aortic homogenate. Diluted aortic homogenate (50 $\mu \mathrm{l})$ was incubated overnight at $4^{\circ} \mathrm{C}$ with $5 \mu \mathrm{g}$ of either rabbit antihuman CEL IgG or rabbit preimmune IgG. The samples were then assayed for CEL activity at $50 \mathrm{mM}$ cholate as described in Methods. The reactions were done in triplicate and mean values \pm SD are displayed. shown in Fig. 5, preincubation of human aortic homogenate with a small amount $(5 \mu \mathrm{g})$ of rabbit anti-human CEL antibody significantly $(P<0.01)$ reduced the hydrolysis of $\mathrm{CE}$ compared with treatment with an equivalent amount of rabbit nonimmune serum.

\section{Discussion}

Besides its role in the digestive process (for review see reference 4), systemic actions of CEL must be considered, given that it circulates in a number a mammalian species $(11,16)$, including humans (15). Since other lipases that circulate have been shown to modify normal human HDL and LDL (e.g., LpL [1] and hepatic lipase [2]), it was natural to investigate whether the lipids on these lipoproteins could be hydrolyzed by CEL. However, one point we needed to take into account was that the millimolar concentrations of bile acid required for maximal hydrolysis of CE and TG in the intestine are not found in either plasma or interstitial fluid. Instead, in systemic plasma the concentration of bile acid is $\sim 10 \mu \mathrm{M}$ (48) and in postprandial portal plasma is $\sim 10$-fold greater (49). Since both of these concentrations are well in excess of the nanomolar levels shown to affect the conformation of CEL (51), it was certainly possible that, in the $10-100 \mu \mathrm{M}$ range physiologically obtainable outside of the intestine, there would be sufficient enzymatic activity to hydrolyze significant amounts of lipoprotein-associated $\mathrm{CE}$ and TG.

As summarized in Tables II and III, this was indeed the case. Interestingly, the rates of hydrolysis (Table II) varied dramatically by mode of presentation (EtOH, $\left.\mathrm{HDL}_{3}, \mathrm{LDL}\right)$. The hydrolysis of lipoprotein-associated CE and TG in the absence of cholate is consistent with the studies of Brockman and colleagues (e.g., reference 52), who have shown that some CEL-mediated hydrolysis can occur in the absence of bile salts, depending on the characteristics of the substrate/enzyme interface. At either the 10 or $100 \mu \mathrm{M}$ cholate concentration, the hydrolysis of both $\mathrm{CE}$ and TG associated with $\mathrm{HDL}_{3}$ was much lower than when the corresponding substrate was presented in either EtOH or associated with LDL.

There are reports that with other lipases there was also differential hydrolysis of HDL and LDL lipids (e.g., references 18 and 53). For example, using a fungal cholesteryl esterase, under conditions in which LDL-CE (as percentage of total cholesterol) went from 75 to $6 \%$, the corresponding values for HDL-CE were 79 and $65 \%$ (18). Factors such as packing density, surface charge, and apoprotein composition, all different between $\mathrm{HDL}_{3}$ and LDL, probably affect the interaction of CEL (and the other enzymes) with lipoproteins as well as the availability to the enzymes of the substrates. In addition to the data in Tables II and III just alluded to, that such factors exert important influences on the interaction of CEL with LDL and $\mathrm{HDL}_{3}$ is also indicated by some simple calculations (based on data in reference 54): The CE content of human LDL is 1,310 molecules/particle. Assuming a surface pool of CE of $3 \mathrm{~mol} \%$, the fraction of total LDL-CE that would be the functional substrate for the enzyme would be 20 surface molecules/1,310 total molecules, or $1.5 \%$. The remaining $98.5 \%$ would be a "substrate reservoir." A similar calculation for $\mathrm{HDL}_{3}$ is a total CE content of 32 molecules/particle and 4 surface molecules, for a fractional functional substrate of $4 / 32$, or $12.5 \%$. Thus, in contrast to what was observed (Table II), the initial rate of hydrolysis of $\mathrm{HDL}_{3}-\mathrm{CE}$ should have been 8 (i.e., $12.5 \% / 1.5 \%$ ) times 
greater than that of LDL-CE. The fact that LDL-CE was the better substrate for CEL (Tables II and III) implies that the enzyme interacts with this particle better than with $\mathrm{HDL}_{3}$.

The potential consequences of the action of CEL on the structural and functional properties of LDL and HDL are suggested by a number of studies. First, the core content of either $\mathrm{CE}$ or TG has been shown recently to affect the $\alpha$-helical content of HDL-apo AI and the stabilities of both the apo AI and the HDL particle itself (Sparks, D.L., W.S. Davidson, S. LundKatz, and M.C. Phillips, manuscript submitted for publication). Such changes could, in turn, affect the ability of HDL to accept cellular cholesterol or to serve as a substrate for LCAT (55). This may be the basis for our previous finding that HDL added to medium containing CEL secreted from transfected rat hepatoma cells promoted greater clearance of cellular cholesterol compared with the clearance from nonsecreting control hepatoma cells (56).

In Aviram et al. (19), hydrolysis of $\sim 1 / 3$ of LDL-CE by a bacterial enzyme resulted in a smaller particle and a $30 \%$ reduction in lipoprotein binding and degradation by the J774 macrophage-like cell line. The authors concluded that these results were a consequence of conformational changes in apo $\mathrm{B}$ due not only to a reduction of core $\mathrm{CE}$ but also to a redistribution of the free cholesterol between the core and the surface of the lipoprotein. In Chao et al. (18), HDL and LDL were pretreated with trypsin, and CE was hydrolyzed by a fungal enzyme. Extensive hydrolysis of LDL-CE resulted in the formation of large multilamellar free cholesterol-rich structures resembling particles that accumulate in atherosclerotic lesions.

Hydrolysis of core TG of HDL and LDL has also been investigated previously. Aviram et al. (2) treated LDL with LpL. In contrast to the results above, the modified LDL had a higher affinity for the LDL receptor. While the authors reconciled the results of their two papers by noting that predominately the core of the LDL is modified by LpL, whereas both the core and surface were modified by CE hydrolysis, a more likely explanation comes from later work of Williams et al. (47) and others (e.g., references 57 and 58) showing that LpL bound to LDL can act as a structural bridge to cell-surface proteoglycans. This would be consistent with the findings of Aviram et al. (2) that in the mathematical analysis of the binding of LpL-modified LDL to macrophages there was evidence for an increase in binding sites. It may be that a similar phenomenon will be observed for CEL-modified lipoproteins, since CEL has a heparin binding site that has been reported to promote the interaction of the enzyme with proteoglycans (17). This would explain the report that CEL enhanced the delivery of a nonhydrolyzable core lipid of HDL (cholesteryl ether) to hepatoma cells (20).

While many studies have focused on CEL as a triglyceride lipase and a cholesteryl ester hydrolase, it should be noted that it was originally cloned as a pancreatic lysophospholipase (21) and subsequently shown to be the only enzyme secreted by the pancreas with this activity (59). Unlike its other catalytic functions, there is no bile salt dependence under any condition for the hydrolysis of lysophospholipids. One major lysophospholipid with relevance to atherogenesis is lysoPC. OxLDL is enriched in lysoPC, which is thought to mediate deleterious effects in arterial tissue mainly by serving, for example, as a chemoattractant that recruits monocytes to the subintimal space (22) or as an antagonist of endothelial-dependent relaxation (24).
In a set of studies, Henry and colleagues $(24,25)$ have shown that the treatment of OxLDL with a bacterial lysophospholipase reduces not only the lysoPC content but also restores the endothelial-dependent relaxation response to acetylcholine of rabbit aortic rings. As shown in Fig. 3, we confirmed the ability of the bacterial enzyme to reduce OxLDL lysoPC content and also showed comparable effectiveness of CEL.

Since oxidation of LDL is not thought to occur in the plasma compartment but after LDL enters the subintimal space, to serve as a potential protective factor against lysoPC the optimal location of CEL for this function would be in arterial tissue. The partial purification of an enzymatic activity in rat and rabbit aortae $(13,14)$ with characteristics of pancreatic CEL encouraged us to examine human samples. That bona fide CEL was present was supported by $(a)$ the stimulation of the cholesteryl ester hydrolase activity by only trihydroxy bile salt and not other detergent molecules (Fig. 4), a particularly characteristic feature of this enzyme (e.g., reference 5); and (b) the inhibition of homogenate activity by preincubation with a specific antibody $(40,41)$ directed against human CEL (Fig. 5). The source of arterial CEL could be multiple; it could be derived from the circulating pool or it could be endogenously synthesized and secreted by one or more of the cell types (e.g., leukocytes [60], smooth muscle, endothelium) present in the tissue. Further studies using immunohistochemistry and in situ hybridization will be necessary to determine the source of aortic CEL activity. It should be noted that others have also reported a non-CEL cholesteryl ester hydrolase activity in the aorta or its component cells (e.g., references 2 and 61). This activity resembles that of hormone-sensitive lipase, in that it is maximally active at neutral $\mathrm{pH}$ and is stimulated by cAMP. We do not think that this contributed significantly to the results in human aortic homogenate, however, since a millimolar concentration of cholate inhibits hormone-sensitive lipase-like activity (reference 62 and Zolfaghari, R., and E.A. Fisher, unpublished results).

The relatively long half-lives of LDL and HDL $(\sim 3 \mathrm{~d})$ in the human circulation (for review see reference 50) and the even greater half-lives of retained lipoproteins in the subintimal space of the aorta (for review see reference 63) imply that there may be significant modification of normal and oxidized lipoproteins by CEL, even for the more refractory substrates on HDL. For OxLDL, CEL is likely to be a protective factor, given its ability to reduce lysoPC content. For normal lipoproteins, it is not clear whether CEL modification would be beneficial or deleterious. For example, it could lead to the formation of LDL particles with increased cellular binding affinity (resulting in increased cellular cholesterol content) or denser LDL particles having increased access to the aortic subintimal space. On the other hand, LDL binding could be reduced (see reference 19) and/or efflux to HDL could be increased (56), both phenomena serving to decrease the net cellular cholesterol content. Nevertheless, our results clearly establish the potential for CEL to exert important effects on lipid metabolism outside of the intestinal lumen and support the undertaking of further studies to define the overall impact of the systemic activity on the development of atherosclerosis.

\section{Acknowledgments}

We thank Dr. Howard L. Brockman (Hormel Institute, University of Minnesota, Austin, MN) for the gift of purified CEL; Dr. Elizabeth 
Laposata (Medical Examiner's Office, Wilmington, DE) for providing autopsy samples while she was at the Hospital of the University of Pennsylvania; Ms. Jill Feltheimer Fisher for valuable editorial assistance; and our colleagues in the Department of Biochemistry, Dr. Michael C. Phillips and Dr. Earl H. Harrison, for helpful discussions. The technical assistance of Ms. Christine E. Ackerman and Ms. Katmna Katiyar and the contribution of Dr. Camilo Rojas to the aortaantibody experiments are also appreciated.

These studies were supported by the National Institutes of Health (DK-44498, HL-22633, HL-07443, HL-45306), the Howard Heinz Endowment, the American Heart Association (South Eastern Pennsylvania affiliate), and the W.W. Smith Charitable Trust (grant H9301).

\section{References}

1. Bamberger, M., S. Lund-Katz, M.C. Phillips, and G.H. Rothblat. 1985. Mechanism of the hepatic lipase induced accumulation of high-density lipoprotein cholesterol by cells in culture. Biochemistry. 24:3693-3701.

2. Aviram, M., E.L. Bierman, and A. Chait. 1988. Modification of low density lipoprotein by lipoprotein lipase or hepatic lipase induces enhanced uptake and cholesterol accumulation in cells. J. Biol. Chem. 263:15416-15422.

3. Labeque, R., C.J.P. Mullon, J.P.M. Ferreira, R.S. Lees, and R. Langer. 1993. Enzymatic modification of plasma low density lipoproteins in rabbits: a potential treatment for hypercholesterolemia. Proc. Natl. Acad. Sci. USA. 90: 3476-3480

4. Wang, C.-S., and J.A. Hartsuck. 1993. Bile salt-activated lipase. A multiple function lipolytic enzyme. Biochem. Biophys. Acta. 1166:1-19.

5. Zolfaghari, R., E.H. Harrison, A.C. Ross, and E.A. Fisher. 1989. Expression in xenopus oocytes of rat liver mRNA coding for a bile salt-dependent cholesteryl ester hydrolase. Proc. Natl. Acad. USA. 86:6913-6916.

6. Zolfaghari, R., E.H. Harrison, J.H. Han, W.J. Rutter, and E.A. Fisher. 1992. Tissue and species differences in bile salt-dependent neutral cholesteryl ester hydrolase activity and gene expression. Arteriosclerosis \& Thromb. 12: 295-301.

7. Camulli, E.D., M.J. Linke, H.L. Brockman, and D.Y. Hui. 1989. Identity of a cytosolic neutral cholesterol esterase in rat liver with the bile salt stimulated cholesterol esterase in pancreas. Biochim. Biophys. Acta. 1005:177-182.

8. Baba, T., D. Downs, K.W. Jackson, J. Tang, and C.-S. Wang. 1991. Structure of human milk bile salt activated lipase. Biochemisry. 30:500-510.

9. Winkler, K.E., E.H. Harrison, J.B. Marsh, J.M. Glick and A.C. Ross. 1992. Characterization of a bile salt-dependent cholesteryl ester hydrolase activity secreted from HepG2 cells. Biochim. Biophys. Acta. 1126:151-158.

10. Chen, L., and R. Morin. 1971. Purification of a human placental cholesteryl ester hydrolase. Biochim. Biophys. Acta. 231:194-197.

11. Harrison, E.H. 1988. Bile salt-dependent, neutral cholesteryl ester hydrolase of rat liver: possible relationship with pancreatic cholesteryl ester hydrolase. Biochim. Biophys. Acta. 963:28-34

12. Rea, T.J., R.B. DeMattos, and M.E. Pape. 1993. Hepatic expression of genes regulating lipid metabolism in rabbits. J. Lipid Res. 34:1901-1910.

13. Kothari, H.V., B.F. Miller, and D. Kritchevsky. 1973. Aortic cholesterol esterase: characteristics of normal rat and rabbit enzyme. Biochim. Biophys. Acta. 296:446-454.

14. Kothari, H.V., and D. Kritchevsky. 1975. Purification and properties of aortic cholesteryl ester hydrolase. Lipids. 10:322-330.

15. Lombardo, D., G. Montalto, S. Roudani, E. Mas, R. Laugier, V. Sbarra, and N. Abouakil. 1993. Is bile salt-dependent lipase concentration in serum of any help in pancreatic cancer diagnosis? Pancreas. 8:581-588.

16. Goldberg, I.J., W.S. Blaner, and D.S. Goodman. 1986. Immunologic and enzymatic comparisons between human and bovine lipoprotein lipase. Arch. Biochem. Biophys. 24:580-584.

17. Bosner, M.S., T. Gulick, D.J.S. Riley, C.A. Spilburg, and L.G. Lange III. 1988. Receptor-like function of heparin in the binding and uptake of neutral lipids. Proc. Natl. Acad. Sci. USA. 85:7538-7442.

18. Chao, F.-F., E.J. Blanchette-Mackie, V.V. Tertov, S.I. Skarlatos, Y.-J. Chen, and H.S. Kruth. 1992. Hydrolysis of cholesteryl ester in low density lipoprotein converts this lipoprotein to a liposome. J. Biol. Chem. 267:4992-4998.

19. Aviram, M., S. Keidar, M. Rosenblat, and G.J. Brook. 1991. Reduced uptake of cholesterol esterase-modified low density lipoprotein by macrophages. J. Biol. Chem. 26:11567-11574.

20. Hui, D.Y., and Y. Huang. 1989. Cholesterol esterase mediated uptake of high density lipoprotein-associated cholesteryl ester by HepG2 cells. Circulation. 80:II-334a. (Abstr.)

21. Han, J.H. C. Stratowa, and W.J. Rutter. 1987. Isolation of full-length putative rat lysophospholipase cDNA using improved methods for mRNA isolation and cDNA cloning. Biochemistry. 26:1617-1625.

22. Quinn, M.T., S. Parthasarathy, and D. Steinberg. 1988. Lysophosphatidylcholine: a chemotactic factor for human monocytes and its potential role in atherogenesis. Proc. Natl. Acad. Sci. USA. 85:2805-2809.
23. Sakai, M., A. Miyazaki, H. Hakamata, T. Sasaki, S. Yui, M. Yamazaki, M. Shichiri, and S. Horiuchi. 1994. Lysophosphatidylcholine plays an essential role in the mitogenic effect of oxidized low density lipoprotein on murine macrophages. J. Biol. Chem. 269:31430-31435.

24. Kugiyama, K., S.A. Kerns, J.D. Morrisett, R. Roberts, and P.D. Henry. 1990. Impairment of endothelium-dependent arterial relaxation by lysolecithin in modified low-density lipoproteins. Nature (Lond.). 344:160-162.

25. Mangin, E.L., Jr., K. Kugiyama, J.H. Nguy, S.A. Kerns, and P.D. Henry. 1993. Effects of lysolipids and oxidatively modified low density lipoprotein on endothelium-dependent relaxation of rabbit aorta. Circ. Res. 72:161-166.

26. Holvoet, P., and D. Collen. 1994. Oxidized lipoproteins in atherosclerosis and thrombosis. FASEB (Fed. Am. Soc. Exp. Biol.) J. 8:1279-1284.

27. Rudd, E.A., N.K. Mizuno and H.L. Brockman. 1987. Isolation of two forms of carboxylester lipase (cholesterol esterase) from porcine pancreas. Biochim. Biophys. Acta. 918:106-114.

28. Hatch, F.T., and R.S. Lees. 1968. Practical methods for plasma lipoprotein analysis. Adv. Lipid Res. 6:1-68.

29. Havel, R.J., H.A. Eder, and J.H. Bragdon. 1955. The distribution and chemical composition of ultracentrifugally separated lipoproteins in human serum. J. Clin. Invest. 34:1345-1353.

30. Scanu, A.M., and C. Edelstein. 1971. Solubility in aqueous solutions of ethanol of the small molecular weight peptides of the serum very low density and high density lipoproteins: relevance to the recovery problem during delipidation of serum lipoproteins. Anal. Biochem. 44:576-588.

31. Lund-Katz, S., and M.C. Phillips. 1984. Packing of cholesterol molecules in human high-density lipoproteins. Biochemistry. 23:1130-1138.

32. Krieger, M., M.S. Brown, J.R. Faust, and J.L. Goldstein. 1978. Replacement of endogenous cholesteryl esters of low density lipoprotein with exogenous cholesteryl linoleate. J. Biol. Chem. 253:4093-4101.

33. Bligh, E.G., and W.J. Dyer. 1959. A rapid method of total lipid extraction and purification. Can. J. Biochem. Physiol. 37:911-917.

34. Sokoloff L., and G.H. Rothblat. 1974. Sterol to phospholipid molar ratio of L-cells with qualitative and quantitative variations of cellular sterols. PSEM (Proc. Soc. Exp. Biol. Med.). 146:1166-1172.

35. Markwell, M.A., S.M. Haas, L.L. Bieber, and N.E. Tolbert. 1978. A modification of the Lowry procedure to simplify protein determination in membrane and lipoprotein samples. Anal. Biochem. 87:206-210.

36. Johnson, W.J., G.K. Chacko, M.C. Phillips, and G.H. Rothblat. 1990. The efflux of lysosomal cholesterol from cells. J. Biol. Chem. 265:5546-5553.

37. Parthasarathy, S., J.C. Khoo, E. Miller, J. Barnett, J.L. Witztum, and D. Steinberg. 1990. Low density lipoprotein rich in oleic acid is protected against oxidative modification: implications for dietary prevention of atherosclerosis. Proc. Natl. Acad. Sci. USA. 87:3894-3898.

38. Morel, D.W., J.R. Hessler, and G.M. Chisolm. 1983. Low density lipoprotein cytotoxicity induced by free radical peroxidation of lipid. J. Lipid Res. 24:1070-1076.

39. Blaner, W.S., J.H. Prystowsky, J.E. Smith, and D.S. Goodman. 1984. Rat liver retinyl palmitate hydrolase activity: relationship to cholesteryl oleate and triolein hydrolase activities. Biochim. Biophys. Acta. 794:419-427.

40. Abouakil, N., E. Rogalska, J. Bonicel, and D. Lombardo. 1988. Purification of pancreatic carboxylic ester hydrolase by immunoaffinity and its application to the human bile salt-stimulated lipase. Biochim. Biophys. Acta. 961:299308.

41. Mas, E., N. Abouakil, S. Roudani, J.L. Franc, J. Montreuil, and D. Lombardo. 1993. Variation of the glycosylation of human pancreatic bile-saltdependent lipase. Eur. J. Biochem. 216:807-812.

42. Van den Bosch, H., J.G.N. de Jong, and A.J. Aarsman. 1991. Lysophospholipases from bovine liver. Methods Enzymol. 197:468-475.

43. Trout, D.L., E.H. Estes, Jr., and S.J. Friedberg. 1960. Titration of free fatty acids of plasma: a study of current methods and a new modification. $J$. Lipid Res. 1:199-202.

44. Kern, P.A., R.A. Martin, J. Carty, I.J. Goldberg, and J.M. Ong. 1990. Identification of lipoprotein lipase immunoreactive protein in pre- and postheparin plasma from normal subjects and patients with type I hyperlipoproteinemia. J. Lipid Res. 31:17-26.

45. Herbert, P.N., G. Assmann, A.M. Gotto, Jr., and D.S. Fredrickson. 1983. Familial lipoprotein deficiency. In The Metabolic Basis of Inherited Disease, Fifth Edition. J.B. Stanbury, J.B. Wyngaarden, J.L. Goldsein, and M.S Brown, editors. McGraw Hill, New York. 591-596.

46. Williams, K.J., K.A. Petrie, R.W. Brocia, and T.L. Swenson. 1991. Lipoprotein lipase modulates net secretory output of apolipoprotein B in vitro. $J$. Clin. Invest. 88:1300-1306.

47. Williams, K.J., G.M. Fless, K.A. Petrie, M.L. Snyder, R.W. Brocia, and T.L. Swenson. 1992. Mechanisms by which lipoprotein lipase alters cellular metabolism of lipoprotein(a), low density lipoprotein, and nascent lipoproteins. $J$. Biol. Chem. 267:13284-13292.

48. Campbell, C.B., C. McGuffie, and L.W. Powell. 1975. The measurement of sulphated and non-sulphated bile acids in serum using gas-liquid chromatography. Clin. Chim. Acta. 63:249-262.

49. Angelin, B., I. Björkhem, K. Einarsson, and S. Ewerth. 1982. Hepatic uptake of bile acids in man. J. Clin. Invest. 70:724-731.

50. Margolis, S., and D. Capuzzi. 1972. Serum-lipoprotein synthesis and me- 
tabolism. In Blood Lipids and Lipoproteins: Quantitation, Composition, and Metabolism. G.J. Nelson, editor. Wiley-Interscience, New York. 851-854.

51. Jacobson, P.W., P.W. Wiesenfeld, L.L. Gallo, R.L. Tate, and J.C. Osborne, Jr. 1990. Sodium cholate-induced changes in the conformation and activity of rat pancreatic cholesterol esterase. J. Biol. Chem. 265:515-521.

52. Tsujita, T., J.M. Muderhwa, and H.L. Brockman. 1989. Lipid-lipid interactions as regulators of carboxylester lipase activity. J. Biol. Chem. 264:86128618.

53. Shirai, K., R.L. Barnhart, and R.L. Jackson. 1981. Hydrolysis of human plasma high density lipoprotein 2-phospholipids and triglycerides by hepatic lipase. Biochem. Biophys. Res. Commun. 100:591-599.

54. Shen, B.W., A.M. Scanu, and F.J. Kézdy. 1977. Structure of human serum lipoproteins inferred from compositional analysis. Proc. Natl. Acad. Sci. USA. 74:837-841.

55. Sparks, D.L., G.M. Anantharamaiah, J.P. Segrest, and M.C. Phillips. 1995. Effect of the cholesterol content of reconstituted LpA-I on lecithin: cholesterol acyltransferase activity. J. Biol. Chem. 270:5151-5157.

56. Zolfaghari, R., J.M. Glick, and E.A. Fisher. 1993. The effects of varying the expression of a neutral cholesteryl ester hydrolase on the turnover of cho- lesteryl ester in rat hepatoma cells. J. Biol. Chem. 268:13532-13538.

57. Rumsey, S.C., J.C. Obunike, Y. Arad, R.J. Deckelbaum, and I.J. Goldberg. 1992. Lipoprotein lipase-mediated uptake an degradation of low density lipoproteins by fibroblasts and macrophages. J. Clin. Invest. 90:1504-1512.

58. Eisenberg, S., E. Sehayek, T. Olivecrona, and I. Vlodavsky. 1992. Lipoprotein lipase enhances binding of lipoproteins to heparan sulfate on cell surfaces and extracellular matrix. J. Clin. Invest. 90:2013-2021.

59. Duan, R.D., and B. Borgström. 1993. Is there a specific lysophospholipase in human pancreatic juice? Biochim. Biophys. Acta. 1167:326-330.

60. Holtsberg, F.W., L.E. Ozgur, D.E. Garsetti, J. Myers, R.W. Egan, and M.E. Clark. 1995. Presence in human eosinophils of a lysophospholipase similar to that found in the pancreas. Biochem. J. 309:141-144.

61. Hajjar, D.P., C.R. Minick, and S. Fowler. 1983. Arterial neutral cholesteryl esterase. J. Biol. Chem. 258:192-198.

62. Sakurada, T., H. Orimo, H. Okabe, A. Noma, and M. Murakami. 1976. Purification and properties of cholesterol ester hydrolase from human aortic intima and media. Biochim. Biophys. Acta. 424:204-212.

63. Williams, K.J., and I. Tabas. 1995. The response-to-retention hypothesis of early atherogenesis. Arteriosclerosis \& Thromb. 15:551-561. 